\title{
Improving the Environmental Sustainability of hotel buildings through the analysis of its Life Cycle. Case Study: Balearic Islands. Initial phase.
}

\author{
B. Rosselló, A. Moia, A. Cladera, V. Martinez \\ Departament of Physics-Mechanical Engineering Group \\ Universitat Illes Balears \\ Ctra. Valldemossa, km 7.5 Palma de Mallorca \\ phone: +34 971 171374, fax: +34 97117 3426, e-mail: andreu.moia@uib.es
}

\section{Brief introduction}

Spain currently receives more than 80 million visitors, of which over $50 \%$ are concentrated in the summer months. This increase in population, located mainly in the tourist accommodation, causes a change that alters the normal use of the infrastructure: transport, energy, water and waste management.

In a place like the Balearic Islands, with more than 10 million visitors annually, there is an increase of $31 \%$ of electricity consumption, $60 \%$ of final consumption and $30 \%$ of waste production. The determination of the amount of resources and emissions that occur in tourist facilities, through analysis of their life cycle, opens the door to establishing structural and operational improvements as well as the implementation of renewable energy.

Keywords: Life cycle assessment, life cycle inventory, environmental impact, energy consumption, hotel buildings.

\section{Introduction}

According to the Institute of Tourism Strategy (INESTUR) of the 'Govern Balear' in 2006 the Balearic Islands were visited by more than 12 million tourists [10]. Annually tourism in this region is equivalent to $20 \%$ of total population. As has been pointed out, this increase in population results in increases of final energy consumption and waste production. This fact also derives other impacts, such as increased water consumption and $\mathrm{CO}_{2}$ emissions. These impacts are greater in the summer months. Figure 1 shows the inflow of tourists in the years 2005 and 2006. Figure 2 shows that the production of waste and electricity consumption evolve in parallel throughout the year because they both depend on the actual population.
Figure 1. Evolution of the entry of tourists. 2005-2006.

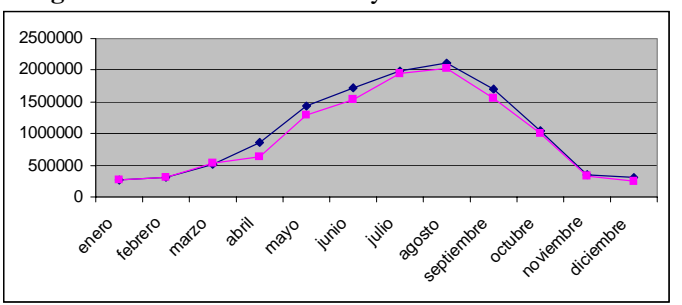

Fuente: INESTUR, 2005-2006.

Figure 2. Electricity and waste production in the Balearic Islands.

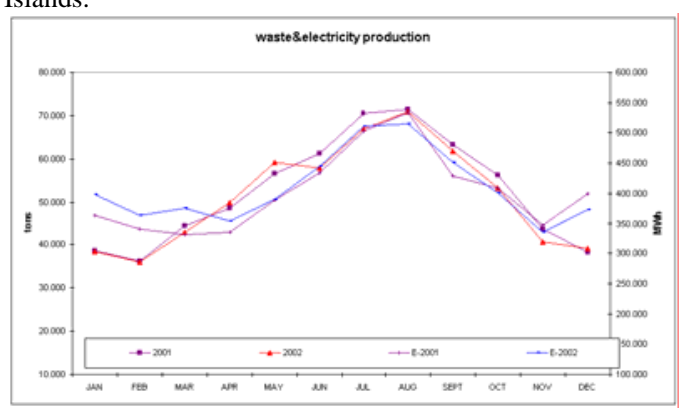

The number of tourist beds in the year 1980 stood at 228.765, in the year 2006 at 423.259. The upward trend of it, with an average annual increase of 2,24\% between those years, makes really necessary a proposal for improvements intended to create a more sustainable tourism.

Figure 3. Evolution of number of establishments and the number of tourist beds in the Balearic Islands, from 1980 until 2006.

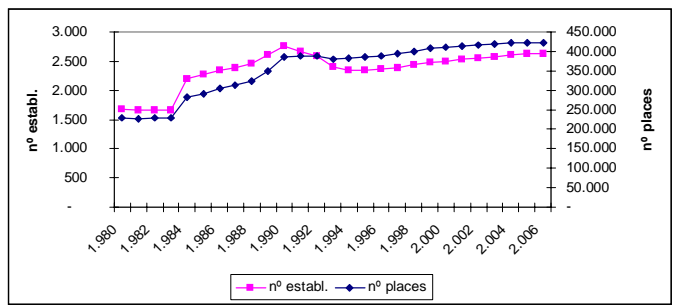

Source: INESTUR, “Dades Informatives 2006”.

Within the tertiary sector hotels are buildings which consume most of the final energy in the EU, with an average of $273 \mathrm{kWh} / \mathrm{m} 2$.

One of the most significant potential to reduce the total energy consumption of a hotel is in the thermal uses, which represent more than $73 \%$ of the final energy used by tourist establishments. 
One of the most important thermal uses is the production of hot water and refrigeration.

Figure 4. Final energy consumption of buildings in the tertiary sector. Evolution from 1980 to 2000.

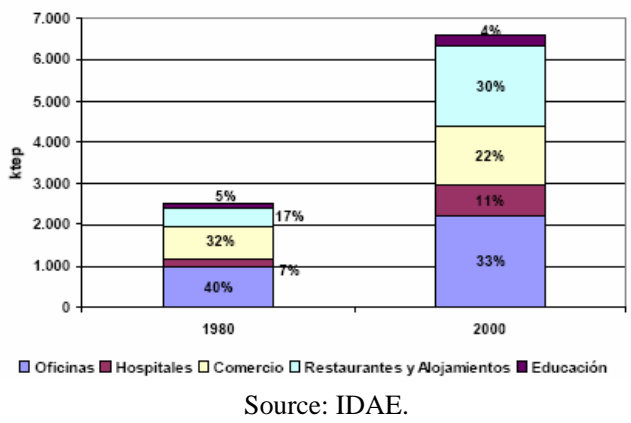

\section{Objectives}

The fundamental goal of this project is to improve the sustainability of tourist establishments on the Balearic Islands. To do so the methodology of Life Cycle Analysis (LCA) is going to be applied. The use of this methodology allows establishing global environmental impacts from this type of buildings in every stage of their life cycle.

The two basic objectives are:

First, conducting an analysis of tourism and its impact, establishing energy indicators and the types of establishments that operate on the Balearic Islands.

Secondly, obtaining a model that shows clearly the implications of the implementation of each type of equipment in the life cycle. Based on this model the intention is to set up an operational tool, which will be of help in the initial phase of design and the phases of implementation and management.

The study is still in its initial stage; therefore it is not possible to specify for the moment the obtained results. The fundamental objective of this article is, therefore, to establish the methodology to be followed and the difficulties that have been encountered.

\section{Life Cycle Assessment_Brief history}

"Life cycle assessment is a process to evaluate the environmental burdens associated with a product, process, or activity by identifying and quantifying energy and materials used and wastes released to the environment; to assess the impact of those energy and material uses and releases to the environment; and to identify and evaluate opportunities to affect environmental improvements. The assessment includes the entire life-cycle of the product, process, or activity, encompassing extracting and processing raw materials; manufacturing; transportation and distribution; use, re-use, maintenance; recycling, and final disposal”. (SETAC, 1991) [2].

LCA is a relatively new methodology. Its precursors were studies known as REPA (Resource and Environmental Profile Analyses) dating from the late 60 and early 70 . The first REPA were intended primarily to meet the environmental impacts of different types of packaging and waste treatment. The term "Life Cycle Assessment" was adopted in 1990 at the first workshop of the Society of Environmental Toxicology and Chemistry (SETAC). The first article in which appeared a comprehensive methodology for LCA dates from 1992 (Franklin Associates). In 1993 the Environmental Protection Agency (EPA) from USA issued a guidance document for the inventory in LCA studies and in the same year SETAC published the "Code of Practice" and "LCA Sourcebook", in addition they start workshops and meetings to achieve consensus on the methodological aspects. The year 1997 saw the publication of the ISO 14040 series of standards concerning LCA. Since then many studies around the world have been published and have formed partnerships and working groups of LCA in different regions [8].

\section{Case study_Choice of LCA methodology}

In the Balearic Islands there are more than 2.500 tourist establishments, with an average energy consumption of $150 \mathrm{kWh} / \mathrm{m}^{2}$ per year, of which more than $50 \%$ comes from the demand for air conditioning. To be sustainable and competitive in tourism it is necessary to boost research, development and innovation in the management of the tourism industry. A Life Cycle Analysis of tourist establishments will allow having an overall understanding of their impacts upon the environment along their lifetime.

Following the review of the LCA methodology it has been observed that there is still no international consensus established in regard to the methodologies for its realization. There are many methods, software and databases. Some studies use methods developed at some universities, the vast majority of them are governed by the ISO standards, (they are not rigid rules but lay down the guidelines to follow). Other studies use software like Equer or SimaPro, among others. As for databases, it has been observed that the most used are the following: Ecoinvent from Ecoinvent Data Centre, Deam ${ }^{\mathrm{TM}}$ from Ecobilan and CML from Leiden University.

The most important references to start an LCA study have been considered to be: ISO 14040 
series of standards relating to LCA and publications of SETAC.

ISO 14040 series of standards establish the basic guidelines to follow when conducting an LCA study, to ensure the studies are conducted in line with international agreements. In summary, the series of ISO standards relating to LCA are the following:

ISO 14041:1998 sets out the objectives and scope of the study, ISO 14042:2000 sets out the steps to follow in the phase of analysis of impacts, ISO 14043:2000 is a report of findings and recommendations on the study, ISO / TS 14048 sets out the format of the documentation to express data from the systems and processes described in the study. Although there are other lines or patterns that help in conducting a study of LCA[9].

The Society of Environmental Toxicology and Chemistry (SETAC), based in North America, Europe, Asia and South America, is one of the world references in LCA studies. They have many publications that establish the guidelines to follow in every step of an LCA study.

In addition, the European Commission has initiated a project called 'European Platform on LCA' conducted by the Joint Research Centre in collaboration with DG Environment. The first phase of the project started in September 2005 and is foreseen to be concluded in August 2008 [11]. The basic objective of this project is to improve the credibility and good practice of the LCA methodology. It provides further information on the best available techniques and reference databases. In this project there is also a database, called ELCD, which can be used.

\subsection{Method chosen}

In this study it has been decided to follow the guidelines set by SETAC in their reports: 'Guidelines for Life-Cycle Assessment: A "Code of Practice" , [2] and 'Life Cycle Assessment in Building and Construction: a state of the art report, 2003'. The report "Life Cycle Analysis" by P. Fullana and R. Puig [5] is also taken as a reference.

\subsection{Databases}

Databases to be used in this project are as follows: CML of Leiden University, ELCD of the European Platform on LCA and Gemis 4.4 of Oeko-Institut (Institute for Ecology Applied). Also some of the results of LCA studies on building materials will be used. In particular an LCA study on exterior walls made with different materials is going to be used [13], also a study on the LCA of different products derived from cement [12], as well as a study of LCA made for different types of windows (glazing plus frame) [14]. With regard to steel there is a project called 'The World Steel Life Cycle Inventory' in which it is possible to request specific information resources, energy and emissions from the production of various steel products. In 1996, the International Iron and Steel Institute (IISI) launched its innovative worldwide life cycle inventory (LCI) study for steel products. This was the first time that an international LCI study of a specific material had been carried out. The study was updated in 2000 and is currently undergoing its second update, to be completed in 2008 [15].

Finally, in the present project, data from the architectural projects of the studied buildings, as well as results from energy audits are going to be used.

\subsection{Structuring the study}

The life cycle of buildings will be divided into three phases: production of construction materials and other components, use phase of the building and demolition and waste treatment.

Into these three phases, the processes that will be taken into account are the following: the production of construction materials, transportation of building materials, energy and water consumption during the use processes, maintenance and alterations, the decommissioning and demolition of the building and, finally, transport and treatment of waste from construction and demolition.

The construction phase itself is not going to be taken into account. This is why there is a lack of data on energy consumption and waste production. (If finally this phase is taken into account, data will be taken as approximate). Waste generation during the operational phase of the hotels, is not going to be taken into account either, due to the lack of actual data.

Furniture and displacements by plane, boat and car of foreigners will be left beyond the limits of the study.

In the present study the following types of hotels will be considered: beach and city, three and four stars hotels, with their respective combinations. For each type several projects are going to be discussed.

It has been decided to choose these types of hotels because of their greater energy consumption. Figure 5 shows the value of these consumptions. 
Figure 5. Electricity consumption in hotels.

\begin{tabular}{|c|c|c|c|c|}
\hline CATEGORÍA & $\begin{array}{c}\text { EST ABL ECIMIENTOS } \\
\left(\mathrm{N}^{\circ}\right)\end{array}$ & $\begin{array}{l}\text { PLAZAS } \\
\left(N^{0}\right)\end{array}$ & $\begin{array}{c}\text { CONSUMO } \\
\text { ESPECÍFICo } \\
\text { (KWhiplaza.año })\end{array}$ & $\begin{array}{l}\text { CONSUMO } \\
\text { TOTAL } \\
\text { (MWh/año) }\end{array}$ \\
\hline Hoteles de $4^{*}$ y $5^{\star}$ & 121 & 43.272 & 2.220 & 96.064 \\
\hline Hoteles de $3^{\star}$ & 453 & 164.937 & 1.398 & 230.582 \\
\hline Hoteles de $2^{*}$ & -128 & 28.168 & 946 & 26.647 \\
\hline Apartamentos & $=$ & 72.683 & 650 & 47.244 \\
\hline$\Rightarrow$ & 1.136 & 78.783 & 350 & 27.574 \\
\hline TOTAL & 2.312 & 387.843 & & 428.111 \\
\hline
\end{tabular}

Figure 6. Distribution of the hotel capacity on the Balearic Islands. 2006.

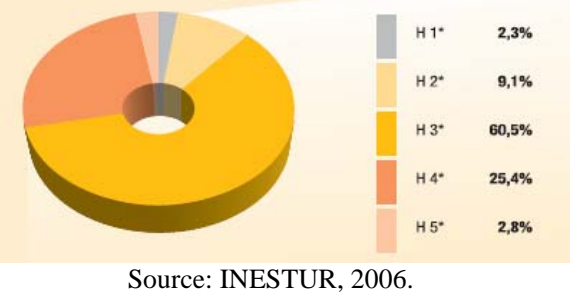

To make it possible to extrapolate the results from some projects to the total hotel buildings it is necessary that these projects are sufficiently representative of the construction on the Islands [7].

The study will be structured according to the following stages (following ISO 14040 standards and guidelines established by SETAC): Goal definition and scoping, inventory analysis, impact assessment, assessment and improvement. Figure 7 shows the interrelation of these components to conduct an LCA study.

Figure 7. Technical Framework for Life-Cycle Assessment.

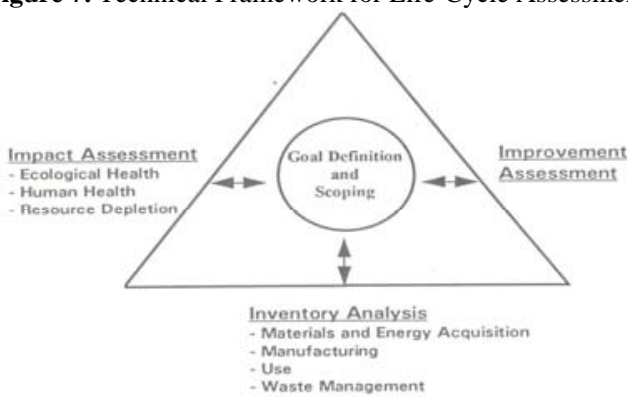

Source: SETAC, 1993.

Next, every stage of the study is going to be commented:

Goal definition and scoping: The fundamental objective of this study is to analyze the environmental impacts resulting from the hotel buildings on the Balearic Islands and the pursuit of improvements to reduce these impacts. This information will be particularly interesting in this region due to the large tourist activity. Furthermore, it is expected that the results could be used in other companies and in other geographic regions. As for the scope of the analysis it must be taken into account that in such a study it is necessary to set limits, because it could extend indefinitely. The system of the study will be hotel buildings of the Islands. As discussed earlier, different types of hotels will be taken into account. Due to the time limitation of the study, it is necessary to limit the number of projects to study. The selected projects must be sufficiently representative of the construction on the Islands.

Within this first phase of the study several important aspects to a good development must be specified. These aspects are listed below and briefly commented: Functional unit: this is one of the most important elements in any study of life cycle. This is the measure of performance that the system under study plays. In this project the following functional unit has been established: $6.000 \mathrm{~m}^{2}$ of hotel with 40 years of lifetime, with capacity for 400 people, with air conditioning and heating oil. The definition of the functional unit is crucial since a LCA does not serve to compare products with each other, but services and / or quantities of product to carry out the same function [17]. Quality of data: It is really difficult to find quality data. This is one of the major difficulties in carrying out a study like this one. Quality of data is set by a number of parameters: geographical origin, the year in which they were derived, accuracy and representativeness, ... The uncertainty of the data is expressed as ranges or diversions. In its treatment can be used methods such as the Matrix Pedigree, Monte Carlo, Lognormal distribution or quadratic diversion calculations. The latter method is the one that is going to be used in this study.

This first phase should be reviewed as the study evolves.

Inventory Analysis: This stage of the study is to take stock of matter and energy of the system. Before carrying out the data collection the system must be divided into subsystems that compose it. The various system components can be displayed through flow-charts, which show the operations carried out. In flow-charts will be included both intermediate transport processes of construction materials and the production of energy [3].

Data collection is not an easy task in an LCA study, especially if the system is as complex as a hotel building. There are many materials to be taken into account, and it is necessary to collect data from all phases of the building lifetime. These data appear in the form of inputs and outputs, and will be obtained, as already mentioned, from surveys conducted in the considered hotels, manufacturers, databases and other studies.

In addition, in the operational phase, data from energy audits conducted in more than 200 hotels are going to be used. These audits contain data from the energy and water consumption. These data can not be used in the analysis of life cycle of a particular project, but they will serve 
to know the actual consumption of a large enough sample of hotels on the Islands and will also serve to recognize the different technologies used. This information will be useful to make comparisons between them and their respective impacts.

As for the data collection of the demolition phase it is important to take into account that the projects for the study are from hotels that are still in operation. Therefore, there are no real data of this phase of the life cycle. This limitation will be solved by using data from studies undertaken in this area. Data quality will be changed depending on the geographical origin of them, among other reasons. As for the demolition waste treatment, preliminary studies have already been conducted for the future use of them. However, it must be borne in mind that the environmental impacts of these treatments will be the corresponding to the current recycling techniques, and it is not possible to establish how they are going to change within the following 40 years, lifetime of the system under study.

Impact Assessment: Impact Assessment in LCA is a technical, quantitative and / or qualitative process to characterize and assess the effects of the environmental burdens identified in the Inventory component. This stage of the LCA consists of a series of steps: classification, characterization and assessment [3].

The classification is the way in which the life cycle inventory data are grouped into a number of impact categories [3]. First of all, it is necessary to decide which impact categories will be considered in the study. These indicators should fill the majority of the impacts of the system and should as much as possible be independent of each other in order to avoid double counting of indirect effect. The list should for practical reasons not contain too many categories [3]. Impact categories chosen for this study are the following: Depletion of resources (ARA, equiv. kg Sb), Global Warming Potential (GWP, equiv. kg CO2), Ozone Depletion Potential (ODP, equiv. kg CFC-11), Acidification Potential (AP, equiv. kg $\mathrm{SO} 2$ ), Eutrophication (NP, equiv. kg PO4), water consumption (in litres) and energy consumption (MJ). In this study indicators of human toxicity or ecotoxity, will not be used.

Characterization is the way in which analysis/quantification, and where possible, aggregation of the impacts within the given impact categories takes place [3]. This process can be carried out according to different methodologies. One of the most commonly used is to add data from the different environmental loads within a category of impact using some compelling factors that are called "characterization factors"[5]. In this study characterization factors published by CML from the University of Leiden will be used. Normalization, included at the stage of characterisation, is an optional step in ISO standards. This phase consists of dividing indicators obtained by a determined value. The reason for doing this is to increase the comparability of the data from the different impact categories and provide a basis for the next step, the valuation [3]. The value used to normalize must be specified in each case. There are Spanish studies that use benchmarks such as those established by the National Emission Limits set for Spain by Directive 2001/81/EC for 2010, or the Limitation of Emission of Greenhouse Gases established in the Kyoto Protocol [8], among others. For each impact category it is necessary to determine what values are most appropriate in the study, taking into account the geographic location or other criteria. Normalization allows a reduction in the number of impacts used.

Valuation: It is the step in which the contributions from the different specific impact categories are weighted so that they can be compared among themselves. The aim of this step is to arrive at a further interpretation and aggregation of the data of the impact assessment [3].

At this stage of the study current profile of electric power production in Spain, is going to be borne in mind because it is subject to change. Indeed, the Observatory of Electricity (newsletter of WWF / Adena), which presents each month magnitudes of the key electric power in Spain, revealed in its edition from last October that, despite the dominance of fossil fuels, $\mathrm{CO}_{2}$ emissions per MWh declined in September 2007, a $7.6 \%$ compared to those recorded in September 2006. This is due to a greater participation of renewable energy in this production. Therefore, according to data of September 2007 the monthly average emission has been $0,351 \mathrm{~kg} \mathrm{CO}_{2}$ per $\mathrm{kW}$ consumed. These results will be taken into account in the study in determining the impact of power consumption.

Improvement assessment: This is the component of an LCA in which options for reducing the environmental impacts or burdens of the system(s) under the study are identified and evaluated. Improvement assessment deals with the identification, evaluation, and selection of options for environmental improvements in products or processes. The inventory analysis may be used to reveal aspects which can be improved [3].

At this stage of the project the buildings studied are going to be simulated. To do it two 
thermal simulation programs have been chosen: TRNSYS16 and CALENER_GT (thermal simulation of buildings). These programs show the influence that materials like insulation, glass and others have on the energy consumption of buildings, and allow verifying the more efficient energy systems. The use of renewable energies, such as solar energy and biomass, are going to be proposed to check reduction of the impacts.

Analyses and interpretation of results: In an LCA study data are not sufficient. It is necessary to explain in detail the findings in terms of the goal and scope defined for the study [3]. As it has been pointed out, in this study no numerical results will be analysed yet. Nevertheless, the most likely outcome is expected to find on the basis of studies undertaken in the field of buildings will be discussed now, in a very general way. According to an LCA study conducted in a building from the University of Michigan [5], the impact of the operational phase is the one that generates more impacts on the lifetime of the building (Figure 8). In the present project, a similar result is expected to be found. Although, it must be borne in mind that the impacts of the construction phase may be slightly higher because of the island character of the region under study and because of the six indicators considered instead of five.

Figure 8. Distributions of life cycle environmental burdens for five impact categories.

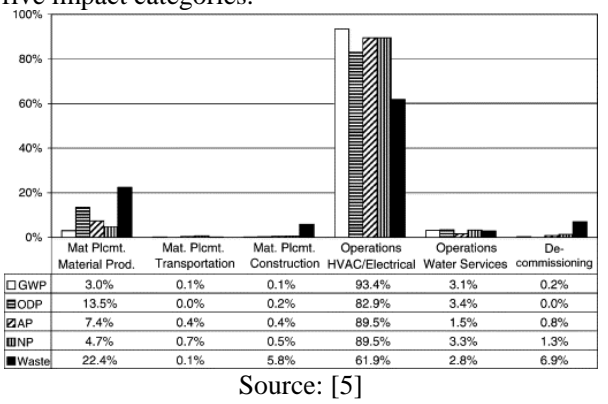

A study conducted in 2003 in buildings from USA and Canada, shows that the impact on materials that constitute a building becomes relatively more important in regions where sources of electricity are predominantly renewable and where energy efficiency factors were taken into account. According to the results obtained in this study, the relative impact of the structure increases when operational impacts decrease. The construction of the structure become more important (in terms of impact) in regions with 'clean' electricity sources, but in absolute terms, however, the impact due to the structure is higher in regions with 'dirty' energy sources [6]. It is important to take this aspect into account when introducing renewable energy in buildings because of the different profile obtained in respect to the one derived from the use of traditional energy sources.

\section{Conclusions}

In general, most of the studies on LCA analyze the impacts over the life cycle of specific products such as tiles or wood, among others. LCA studies on buildings, although growing, are still far less numerous.

Given that much of the current energy consumption comes from the buildings, it is really important to develop studies of this type.

As for the results of the study it is important to bear in mind that they will be determined by the assumptions and limitations set out therein. These limitations, as have been pointed out previously, derive from not considering aspects such as the generation of waste during the operational phase or the displacements of tourists to and from their place of residence or during their stay on the Islands. These constraints must be taken into account when interpreting the results, since their inclusion certainly would change the impacts obtained. In fact, the number of annual visitors is high and, for example, in 2000 the fleet of rental cars stood at 48.000 vehicles (the total number of cars on the Balearic Islands in 2000 was 535.941).

In addition, it is important to keep in mind that all that has been established in this document may be subject to change while the study continues, depending on the difficulties encountered along the way.

It is expected that this research project helps improving the Environment and Tourism in the Balearic Islands. Tourist enterprises of the Balearic Islands are among the world's leaders in the tourism management, so any innovation could be applied to other local business establishments elsewhere in the world, and help to reduce the environmental impacts of this industry.

\section{Acknowledgement}

The authors would like to thank the Direcció General d'Energia of the Balearic Government for financing this study.

\section{References}

[1] A. Moiá-Pol, Michalis Karagiorgas, V. MartínezMoll ,R. Pujol, Carles Riba-Romeva. Evaluation of the Solar Energy and Biomass application in Mediterranean Hotels: Case study: the Balearic Islands. Procc. International Conference of Renewable Energy and Power Quality ICREPQ. Universitat de les Illes Balears.(2006). 
[2] Shpresa Kotaji, Agnes Schuurmans, Suzy Edwards. Life Cycle Assessment in Building and Construction: a state of the art report, 2003. SETAC.

[3] Guidelines for Life-Cycle Assessment: A "Code of Practice". 1993. SETAC.

[4] Towards a Methodology for Life Cycle Impact Assessment. 1996. SETAC.

[5] P.Fullana, R. Puig. Análisis del ciclo de vida. 1997. Ed. Rubes. Barcelona.

[5] Chris Scheuer, Gregory A. Keoleian and Peter Reppe. Life cycle energy cycle energy and environmental performance of a new university building: modeling challenges and design implications. Energy and Buildings, Volume 35, Issue 10, November 2003, Pages 1049-1064.

[6]Artículo: MARK D. WEBSTER et al. 'Relevance of structural engineers to sustainable design of buildings' (Revista 'Structural Engineering International'). 3/2004.

[7] Estudio (Life Lanzarote 2001-2004): Análisis de los materiales empleados en la edificación en la isla de Lanzarote desde una perspectiva medioambiental. (Life Lanzarote 2001-2004)

[8] L.P.Güereca Hernández. Tesis Doctoral: "Desarrollo de una metodología para la valoración en el Análisis del Ciclo de Vida aplicada a la Gestión integral de residuos municipales”. 2006. Barcelona. UPC.

[9] R. Carlson et al. LCA training package for users of LCA data and results. Cascade Project. 2003.

[10] Instituto de Estrategia Turística (INESTUR). http://www.inestur.es/documentos/810_mi.pdf [11] European Platform on LCA: http://lca.jrc.ec.europa.eu/EPLCA/

[12] A. C. De Carvalho Filho. Análisis del ciclo de vida de productos derivados del cemento. Aportaciones al análisis de los inventarios del ciclo de vida del cemento. Tesis doctoral. UPC. 2001.

[13] X. R. Ramon. Estudio de la aplicabilidad de materiales compuestos avanzados en la construcción de edificios industriales. Tesis doctoral. UPC. 2005.

[14] Performance, durability and sustainability of advanced windows and solar components for building envelopes. Final Report. Task 27. Solar Heating and Cooling Program. March 2006.

[15] The 'World Steel Life Cycle Inventory'. http://www.worldsteel.org/?action=storypages\&id=2 $\underline{33}$

[16] J. Rieradevall i Pons. Análisis del Ciclo de Vida. Herramienta de mejora ambiental. UAB.

[17] M.A. Antón Vallejo. Tesis Doctoral: Utilización del Análisis del ciclo de vida en la evaluación del impacto ambiental del cultivo bajo invernadero mediterráneo. UPC. 2004. 